\title{
PENGEMBANGAN PELUMAS RAMAH LINGKUNGAN DENGAN ESTER BORAT
}

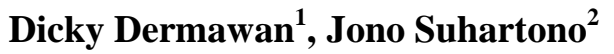 \\ Jurusan Teknik Kimia, Fakultas Teknologi Industri, Institut Teknologi Nasional ${ }^{1,2)}$ \\ Bandung, Jawa Barat \\ E-Mail : 2d@itenas.ac.id
}

\begin{abstract}
This paper reports an attempt to improve the performance of environmentally friendly bio-based lube oil prepared from glycerol and oleic acid. Four variant of boric acid esters, fortified with 2,5dimercapto-1,3,4-thiadiazol, aromatic amine antioxidant, and benzotriazol were used as additives. The oxidation \& corrosion test was carried out using the bulk test at $150^{\circ} \mathrm{C}$ for $24 \mathrm{~h}$. Steel \& copper specimens weight losses and kinematic viscosity increase (measured at $40^{\circ} \mathrm{C}$ and $100^{\circ} \mathrm{C}$ according to ASTM D-445) were used to measure the effect of formulation to the corrosiveness and oxidation stability of the oil, respectively. Experimental results indicated that nitrogen-containing boric acid esters showed better performance in terms of oxidation stability improvement. Slight increases in corrosiveness were shown for all additive systems. Phenyl-1-naphtylamine showed better performance than diphenylamine antioxidant.
\end{abstract}

Keywords : Ester Borat, Pelumas Bio-Based, Stabilitas Oksidasi.

\section{PENDAHULUAN}

Meningkatnya kepedulian pada masalah lingkungan dan energi mengakibatkan spesifikasi minyak lumas yang berkaitan dengan issue-issue lingkungan dan energi seperti biodegradabilitas, toksisitas, kesehatan dan keselamatan, emisi, dan fuel economy semakin ketat. Pelumas bio-based dikembangkan dari minyak nabati melalui berbagai modifikasi seperti esterifikasi / transester ifikasi, hidrogenasi parsial / selektif, oligomerisasi, epoksidasi, atau perubahan struktur kimia lainnya. Pelumas bio-based dapat memegang peranan penting sebagai bahan dasar pelumas yang berada pada kelas tersendiri karena kombinasi antara sifat keterbaruan dan kinerja pelumasannya yang baik.

Di samping indeks viskositasnya yang tinggi, volatilitasnya yang rendah, dan kemampuannya yang baik dalam melarutkan kontaminan dan aditif, gugus polar yang dimiliki minyak nabati membuatnya memiliki sifat amfifilik yang memungkinkan pemakaiannya pada semua rejim pelumasan.
Kebutuhan akan minyak nabati untuk sektor pelumas diperkirakan akan meningkat pada beberapa tahun mendatang (Soni \& Agarwal, 2014).

Ikatan rangkap tak jenuh dalam rantai asam lemak minyak nabati menjadikannya rentan terhadap oksidasi. Hal ini menjadi persoalan utama dalam penggunaannya sebagai minyak lumas. Degradasi oksidatif mengakibatkan kenaikan viskositas sehingga mengakibatkan masa pakainya pendek. Di samping itu, minyak nabati juga memiliki daya perlindungan yang kurang baik terhadap korosi.

Perbaikan ketahanan oksidasi dan perlindungan terhadap korosi serta sifat sifat pelumasan lain secara umum dapat diperoleh melalui formulasi dengan bahanbahan aditif. Aditif pelumas berbasis senyawa boron menarik untuk dipelajari karena sifatnya yang ashless dan kinerjanya yang bersifat multifungsional sehingga diharapkan menjadi kandidat pengganti ZnDTP, aditif multi - fungsional utama yang digunakan pada kebanyakan aplikasi pelumas hingga saat ini. 
Keunggulan lain dari senyawa boron adalah efek sinergistiknya dengan banyak bahan aditif tradisional. Studi formulasi oleh Karol \& Donelly (2011) menyingkap efek sinergistik antara senyawa ester organoborat dengan aditif - aditif yang mengandung sulfur dan fosfor seperti dithiokarbamat, bisdithiokarbamat, 2,5 - dimercapto- 1 ,3,4 thiadiazol (DMTD), fosforodithioat dan esternya, serta senyawa molybdenum nonsulfur yang terbentuk dari molybdenum, minyak nabati, dan diethanolamin. Hu dkk. (2007) menemukan bahwa senyawa boron nitrogen memberikan perbaikan terhadap sifat antiaus dan menunjukkan efek sinergistik dengan $\mathrm{ZnDTP}$ and $\mathrm{SnDTP}$ dalam parafin cair. Studi mekanistik yang mereka lakukan menunjukkan bahwa senyawa boron membentuk lapisan pelindung berupa boron nitrida dan $\mathrm{B}_{2} \mathrm{O}_{3}$ pada permukaan gesek. Shah (2011) menunjukkan bahwa S-di-noctoxyboron-O,O'-di-n-octyldithiophosphate memberikan koefisien gesek dan sifat antiaus yang lebih baik daripada ZnDTP.

Wang dkk (2007) menunjukkan bahwa senyawa ester borat disulfida memberikan sifat antikorosi terhadap tembaga, antioksidan, penurun koefisien gesek dan aus, serta memiliki sifat tekanan ekstrem yang lebih baik daripada olefin tersulfurisasi. Ester asam borat yang dibuat melalui reaksi antara asam borat dengan glikol monoeter dan poliol memiliki sifat sebagai stabiliser dan inhibitor korosi (Sawyer, 1975). Ester yang terbentuk dari asam borat dengan asam hidroksi-karboksilat merupakan aditif peningkat detergensi sekaligus antioksidan (Muir, 2010).

Hasil reaksi antara campuran anhidrida maleat dengan oligomer senyawa olefinik dengan difenilamin dan etanolamin yang direaksikan lebih lanjut dengan asam borat diklaim bermanfaat sebagai aditif peningkat sifat dispersan pelumas (Ashjian, 1991). Farng (1992a) mereaksikan DMTD dengan epoksida membentuk senyawa alkohol yang kemudian diesterkan dengan asam borat. Ester yang terbentuk memiliki sifat multifungsional sebagai aditif anti aus dan antioksidan.
Sifat antioksidan yang efektif diperoleh Farng (1992b) dengan mereaksikan antioksidan fenolik yang mengandung gugus amin dengan asam borat.

Ester borat juga diketahui memiliki sifat sebagai bahan bakteriostatik (biostatik) dan menunjukkan efek inhibisi sinergistik bila dikominasikan dengan senyawa amin (Kirk \& Othmer, 2003).

Rendahnya stabilitas hidrolisis ester borat sering dikemukakan sebagai keterbatasan terbesar yang menghambat aplikasi senyawa ini dalam industri, tetapi beberapa studi menunjukkan bahwa persoalan ini dapat diatasi melalui penggunaan ester borat bersama senyawa yang mengandung nitrogen. Perbaikan stabilitas hidrolisis terjadi karena adanya ikatan kovalen koor-dinasi antara atom boron yang kekurangan pasangan elektron dengan pasangan elektron bebas yang dimiliki nitrogen. Liping dkk (2014) membuat ester borat dari benzotrizol-etanol dan monoetanolamin dan menunjukan bahwa senyawa ini memiliki stabilitas hidrolisis yang baik dalam minyak biji rape dan mampu memberikan penurunan koefisien gesek serta menurunkan aus akibat gesekan. Wang (2008) menggunakan asam fenilboronat sebagai sumber boron untuk menghasilkan aditif multifungsional dithiofosfat yang stabil terhadap hidrolisis.

Stabilitas terhadap hidrolisis juga dapat diperoleh dengan cara mereaksikan boron dengan senyawa aromatik karena kecenderungan ikatan $\pi$ dari cincin aromatic untuk menyumbang elektron. Yan dkk. menunjukkan bahwa senyawa tris (4dodecylfenil) borat yang tidak mengandung nitrogen bahkan memiliki stabilitas hidrolitik yang lebih baik daripada senyawa serupa yang mengandung nitrogen (Yan dkk, 2014).

Efektivitas aditif merupakan fungsi dari jenis bahan dasar, struktur aditif, serta bahan lain yang terkandung dalam pelumas, sehingga struktur ester borat mana yang paling efektif berperan sebagai aditif pada pelumas bio-based yang sedang kami kembangkan perlu dipelajari. 
Pada penelitian ini dipelajari 4 macam ester borat, dua varian diantaranya merupakan ester borat yang disenyawakan dengan bahan dasar (tetapi dengan proses berbeda), sedangkan dua varian lainnya merupakan ester borat dengan senyawa yang mengandung nitrogen, yaitu monoetanolamin dan dietanolamin.

\section{METODOLOGI PENELITIAN 2.1.Pelumas Bio-based}

Proses pembuatan melibatkan reaksireaksi polimerisasi gliserol, stabilisasi asam oleat, dan esterifikasi antara kedua produk reaksi sebelumnya. Semua percobaan dilakukan secara batch pada tekanan atmosferik inert $\mathrm{N}_{2}$.

Polimerisasi gliserol dilangsungkan pada suhu $250^{\circ} \mathrm{C}$ selama 2 - 3 jam dengan bantuan katalis $\mathrm{NaOH}$ sebanyak $1 \%$ berat. Stabilisasi asam oleat dilangsungkan pada suhu $230^{\circ} \mathrm{C}$ dengan bantuan katalis zeolit.

Bahan dasar pelumas bio-based merupakan hasil esterifikasi antara produk reaksi - reaksi di atas pada suhu $160^{\circ} \mathrm{C}$ $240^{\circ} \mathrm{C}$. Reaksi diikuti melalui pengamatan terhadap kondensat air yang dihasilkan. Reaksi dilangsungkan semalaman agar berlangsung hingga sempurna.

\subsection{Ester Borat}

Empat varian ester borat dibuat untuk diuji pelumas bio-based yang dijelaskan di atas. Proses pembuatan keempat varian ditunjukkan pada gambar 1 . Ester borat A dibuat sebagaimana cara membuat bahan dasar, tetapi pada proses esterifikasinya ditambahkan pula asam borat. Ester borat B dibuat dengan cara mereaksikan bahan dasar yang telah dibuat dengan asam borat. Ester borat $\mathrm{C}$ dibuat dengan dengan urutan : (i) mereaksikan asam borat dengan monoetanolamin (ii) mereaksikan produk ini dengan bahan dasar. Ester borat $\mathrm{D}$ dibuat seperti ester borat $\mathrm{C}$, tetapi memakai dietanolamin.

\subsection{Aditif Lain}

DMTD yang digunakan pada formulasi merupakan konsentrat DMTD yang terikat dalam struktur molekul bahan dasar. Mulamula DMTD direaksikan dengan hasil stabilisasi asam oleat semalaman pada suhu $180^{\circ} \mathrm{C}$. Hasil ini kemudian diesterifikasikan dengan poligliserol.

Antioksidan digunakan dalam bentuk yang serupa dengan DMTD. Mula-mula antioksidan (difenilamin atau fenil-1naftilamin) disertakan pada proses stabilisasi asam oleat. Hasil stabilisasi yang mengandung antioksidan ini kemudian diesterifikasikan dengan poligliserol.

Benzotriazol digunakan dalam bentuk konsentrat dalam bahan dasar. Benzotriazol dicampurkan dengan bahan dasar, kemudian dipanaskan selama 30 menit pada suhu $200^{\circ} \mathrm{C}$. 

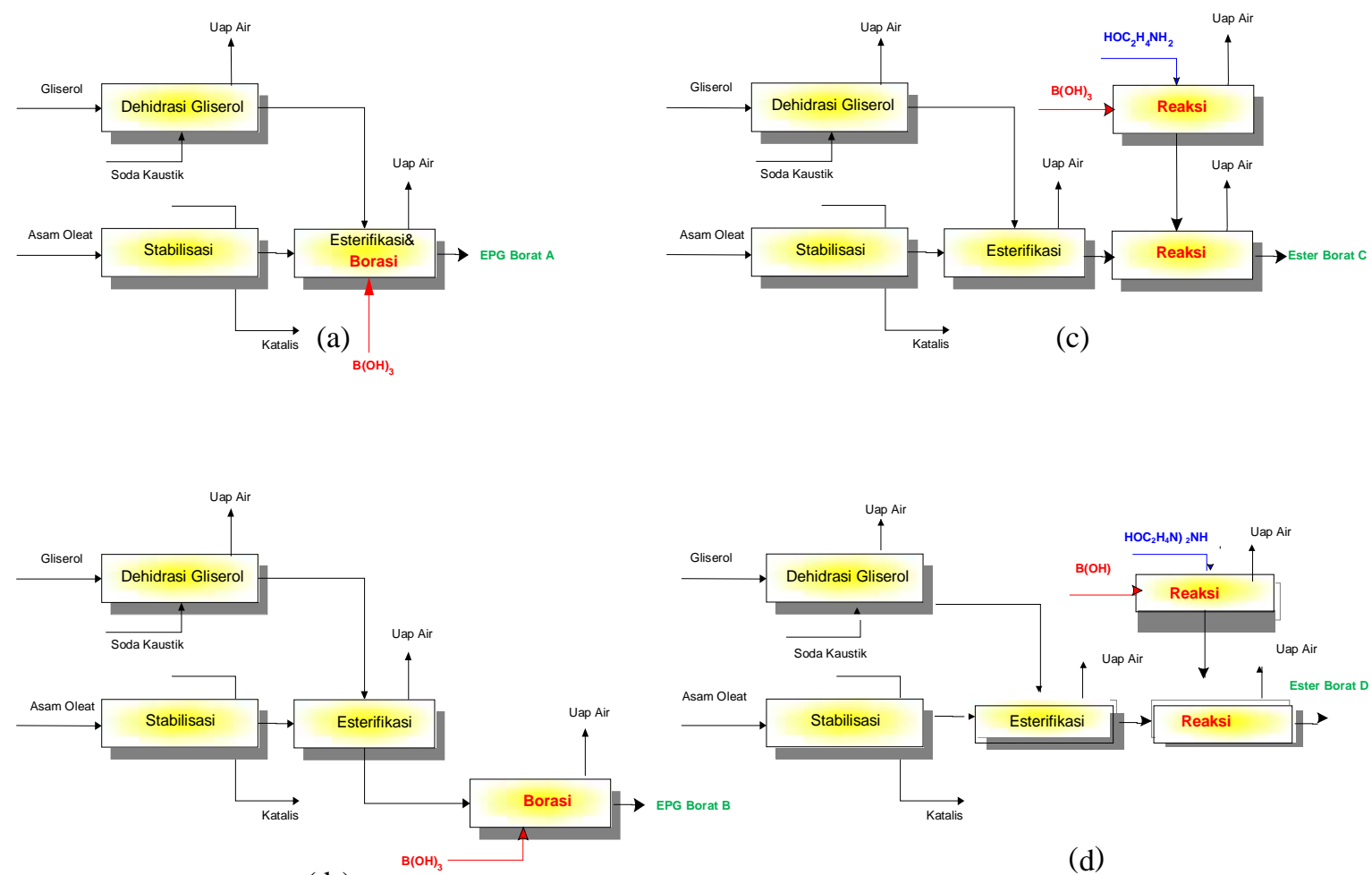

(b)

(d)

Gambar 1. Variasi Proses Pembuatan Ester - ester Borat.

\subsection{Formulasi}

Formulasi pada prinsipnya merupakan pencampuran antara bahan dasar, dengan konsentrat ester borat, antioksidan, dan benzotriazol. Untuk masing - masing ester borat, penggunaan divariasikan $50 \mathrm{ppm}$ atau 100 ppm. Antioksidan yang digunakan adalah difenilamin atau fenil-1-naftilamin pada konsentrasi $1 \%$ atau $2 \%$. Konsentrasi DMTD ditetapkan sehingga campuran mengandung $0,1 \%$ sulfur. Benzotriazol digunakan pada konsentrasi tetap 100 ppm.

\subsubsection{Uji Ketahanan Oksidasi dan Korosivitas}

Sampel sampel sebanyak 120 gram ditempatkan dalam gelas uji yang suhunya dijaga tetap pada $150^{\circ} \mathrm{C}$ dengan cara menempatkannya dalam oil bath berisi silicon oil. Ke dalam sampel dialirkan udara dan ditambahkan specimen logam tembaga dan besi dengan luas permukaan berturutturut 8 in $^{2}$ dan 16 in $^{2}$. Pengujian dilakukan selama 24 jam. Massa specimen besi dan tembaga serta viskositas sampel diukur, sebelum dan sesudah pengujian, pada suhu suhu $40^{\circ} \mathrm{C}$ dan $100^{\circ} \mathrm{C}$. 
Tabel 1. Kinerja Bahan Dasar

\begin{tabular}{cccccc}
\hline $\begin{array}{c}\text { Anti - } \\
\text { Oxidan }\end{array}$ & $\begin{array}{c}\text { Boron } \\
\mathbf{p p m}\end{array}$ & $\begin{array}{c}\text { Kenaikan } \\
\mathbf{4 0}^{\mathbf{0}} \mathbf{C}\end{array}$ & $\begin{array}{c}\text { Viskositas } \\
\mathbf{1 0 0}^{\mathbf{0}} \mathbf{C}\end{array}$ & $\begin{array}{c}\text { Kehilangan } \\
\text { Besi }\end{array}$ & $\begin{array}{c}\text { Massa, mg/in } \\
\text { Tembaga }\end{array}$ \\
\hline Tanpa Aditif & & $133 \%$ & $98 \%$ & 2.9 & 2.8 \\
\hline
\end{tabular}

Tabel 2. Kinerja Borat Ester A

\begin{tabular}{ccccccc}
\hline $\begin{array}{c}\text { Anti - } \\
\text { Oxidan }\end{array}$ & $\%$ & $\begin{array}{c}\text { Boron } \\
\mathbf{p p m}\end{array}$ & $\begin{array}{c}\text { Kenaikan } \\
\mathbf{4 0}^{\mathbf{0}} \mathbf{C}\end{array}$ & $\begin{array}{c}\text { Viskositas } \\
\mathbf{1 0 0}^{\mathbf{0}} \mathbf{C}\end{array}$ & $\begin{array}{c}\text { Kehilangan } \\
\text { Besi }\end{array}$ & $\begin{array}{c}\text { Massa, mg/in } \\
\text { Tembaga }\end{array}$ \\
\hline i-DPA & 1 & 50 & $142 \%$ & $101 \%$ & 3.4 & 3.1 \\
i-DPA & 1 & 100 & $95 \%$ & $65 \%$ & 1.1 & 5.7 \\
i-DPA & 2 & 50 & $98 \%$ & $73 \%$ & 3.7 & 5.6 \\
i-DPA & 2 & 100 & $106 \%$ & $79 \%$ & 3.2 & 5.6 \\
i-PNA & 1 & 50 & $104 \%$ & $79 \%$ & 3.4 & 3.9 \\
i-PNA & 1 & 100 & $115 \%$ & $75 \%$ & 2.9 & 4.1 \\
i-PNA & 2 & 50 & $84 \%$ & $62 \%$ & 3.8 & 4.4 \\
i-PNA & 2 & 100 & $100 \%$ & $71 \%$ & 3.2 & 3.8 \\
\hline Ester Borat $\mathbf{A}$ & & $\mathbf{1 0 6 \%}$ & $\mathbf{7 5 \%}$ & $\mathbf{3 . 1}$ & $\mathbf{4 . 5}$ \\
\hline
\end{tabular}

Tabel 3. Kinerja Borat Ester B

\begin{tabular}{ccccccc}
\hline $\begin{array}{c}\text { Anti - } \\
\text { Oxidan }\end{array}$ & $\%$ & $\begin{array}{c}\text { Boron } \\
\mathbf{p p m}\end{array}$ & $\begin{array}{c}\text { Kenaikan } \\
\mathbf{4 0}^{\mathbf{0}} \mathbf{C}\end{array}$ & $\begin{array}{c}\text { Viskositas } \\
\mathbf{1 0 0}^{\mathbf{0}} \mathbf{C}\end{array}$ & $\begin{array}{c}\text { Kehilangan } \\
\text { Besi }\end{array}$ & $\begin{array}{c}\text { Massa, mg/in } \\
\text { Tembaga }\end{array}$ \\
\hline i-DPA & 1 & 50 & $97 \%$ & $74 \%$ & 3.1 & 6.3 \\
i-DPA & 1 & 100 & $137 \%$ & $85 \%$ & 2.1 & 7.3 \\
i-DPA & 2 & 50 & $151 \%$ & $103 \%$ & 3.4 & 5.2 \\
i-DPA & 2 & 100 & $99 \%$ & $70 \%$ & 2.4 & 5.3 \\
i-PNA & 1 & 50 & $156 \%$ & $101 \%$ & 3.1 & 5.8 \\
i-PNA & 1 & 100 & $100 \%$ & $67 \%$ & 3.5 & 4.6 \\
i-PNA & 2 & 50 & $102 \%$ & $68 \%$ & 3.8 & 4.1 \\
i-PNA & 2 & 100 & $101 \%$ & $76 \%$ & 3.5 & 5.6 \\
\hline \multicolumn{2}{l}{ Ester Borat B } & & $\mathbf{1 1 8 \%}$ & $\mathbf{8 1 \%}$ & $\mathbf{3 . 1}$ & $\mathbf{4 . 5}$ \\
\hline
\end{tabular}

Tabel 4. Kinerja Borat Ester C

\begin{tabular}{ccccccc}
\hline $\begin{array}{c}\text { Anti - } \\
\text { Oxidan }\end{array}$ & $\%$ & $\begin{array}{c}\text { Boron } \\
\mathbf{p p m}\end{array}$ & $\begin{array}{c}\text { Kenaikan } \\
\mathbf{4 0} \mathbf{C}\end{array}$ & $\begin{array}{c}\text { Viskositas } \\
\mathbf{1 0 0}^{\mathbf{0}} \mathbf{C}\end{array}$ & $\begin{array}{c}\text { Kehilangan } \\
\text { Besi }\end{array}$ & $\begin{array}{c}\text { Massa, mg/in } \\
\text { Tembaga }\end{array}$ \\
\hline i-DPA & 1 & 50 & $92 \%$ & $69 \%$ & 3.8 & 6.4 \\
i-DPA & 1 & 100 & $78 \%$ & $63 \%$ & 2.1 & 6.5 \\
i-DPA & 2 & 50 & $105 \%$ & $116 \%$ & 3.4 & 6.1 \\
i-DPA & 2 & 100 & $102 \%$ & $118 \%$ & 2.9 & 6.3 \\
i-PNA & 1 & 50 & $101 \%$ & $71 \%$ & 2.8 & 5.6 \\
i-PNA & 1 & 100 & $65 \%$ & $48 \%$ & 2.8 & 6.0 \\
i-PNA & 2 & 50 & $84 \%$ & $61 \%$ & 3.6 & 4.8 \\
i-PNA & 2 & 100 & $88 \%$ & $62 \%$ & 3.5 & 4.7 \\
\hline Ester Borat C & & $\mathbf{8 9 \%}$ & $\mathbf{7 6 \%}$ & $\mathbf{3 . 1}$ & $\mathbf{5 . 8}$ \\
\hline
\end{tabular}


Tabel 5. Kinerja Borat Ester D

\begin{tabular}{ccccccc}
\hline $\begin{array}{c}\text { Anti - } \\
\text { Oxidan }\end{array}$ & $\%$ & $\begin{array}{c}\text { Boron } \\
\mathbf{p p m}\end{array}$ & $\begin{array}{c}\text { Kenaikan } \\
\mathbf{4 0}^{\mathbf{0}} \mathbf{C}\end{array}$ & $\begin{array}{c}\text { Viskositas } \\
\mathbf{1 0 0}^{\mathbf{0}} \mathbf{C}\end{array}$ & $\begin{array}{c}\text { Kehilangan } \\
\text { Besi }\end{array}$ & $\begin{array}{c}\text { Massa, mg/in } \\
\text { Tembaga }\end{array}$ \\
\hline i-DPA & 1 & 50 & $88 \%$ & $68 \%$ & 3.3 & 6.6 \\
i-DPA & 1 & 100 & $87 \%$ & $64 \%$ & 3.0 & 5.7 \\
i-DPA & 2 & 50 & $104 \%$ & $78 \%$ & 2.9 & 6.4 \\
i-DPA & 2 & 100 & $105 \%$ & $76 \%$ & 3.1 & 6.1 \\
i-PNA & 1 & 50 & $110 \%$ & $72 \%$ & 3.4 & 4.1 \\
i-PNA & 1 & 100 & $84 \%$ & $64 \%$ & 3.6 & 4.2 \\
i-PNA & 2 & 50 & $94 \%$ & $69 \%$ & 4.3 & 5.0 \\
i-PNA & 2 & 100 & $96 \%$ & $65 \%$ & 3.4 & 1.5 \\
\hline Ester Borat D & & $\mathbf{9 6 \%}$ & $\mathbf{6 9 \%}$ & $\mathbf{3 . 2}$ & $\mathbf{4 . 9}$ \\
\hline
\end{tabular}

Tabel 6. Perbandingan Kinerja Antioksidan

\begin{tabular}{|c|c|c|c|c|c|}
\hline Antioxidan & $\%$ & $\begin{array}{c}\text { Kenaikan } \\
\mathbf{4 0}^{\circ} \mathrm{C}\end{array}$ & $\begin{array}{c}\text { Viskositas } \\
100^{\circ} \mathrm{C}\end{array}$ & $\begin{array}{c}\text { Kehilangan } \\
\text { Besi }\end{array}$ & $\begin{array}{c}\text { Massa, mg/in }{ }^{2} \\
\text { Tembaga }\end{array}$ \\
\hline i-DPA pada Ester A & & $110 \%$ & $79 \%$ & 2.8 & 5.0 \\
\hline i-DPA pada Ester B & & $121 \%$ & $83 \%$ & 2.8 & 6.0 \\
\hline i-DPA pada Ester C & & $94 \%$ & $91 \%$ & 3.0 & 6.3 \\
\hline i-DPA pada Ester D & & $96 \%$ & $71 \%$ & 2.8 & 6.2 \\
\hline Rata - rata i-DPA & & $106 \%$ & $81 \%$ & 2.9 & 5.9 \\
\hline i-PNA pada Ester A & & $101 \%$ & $72 \%$ & 3.3 & 4.0 \\
\hline i-PNA pada Ester B & & $115 \%$ & $78 \%$ & 3.5 & 5.0 \\
\hline i-PNA pada Ester C & & $84 \%$ & $60 \%$ & 3.2 & 5.3 \\
\hline i-PNA pada Ester D & & $96 \%$ & $67 \%$ & 3.7 & 3.7 \\
\hline Rata - rata i-PNA & & $96 \%$ & $69 \%$ & 3.2 & 4.9 \\
\hline
\end{tabular}

Kehilangan massa kedua logam setelah pengujian dijadikan kriteria penilaian korosivitas. Kenaikan viskositas kinematik sampel digunakan sebagai ukuran kestabilan : sampel dengan kenaikan viskositas terkecil merupakan sampel dengan ketahanan oksidasi terbaik.

\section{HASIL DAN PEMBAHASAN}

\subsection{Perbandingan Kinerja Ester Borat}

Tabel 1 menunjukkan hasil uji ketahanan oksidasi dan perlindungan korosi dari bahan dasar (tanpa aditif). Hasil uji ini cukup konsisten dengan hasil-hasil studi sebelumnya yang juga menunjukkan bahwa kenaikan viskositas akibat oksidasi, diukur pada suhu $40^{\circ} \mathrm{C}$, berkisar $123 \%-168 \%$.

Tabel 2 menunjukkan ringkasan kinerja ester borat yang dibuat. Nampak bahwa bila dibandingkan dengan bahan dasarnya, secara umum diperoleh perbaikan ketahanan oksidasi tetapi disertai dengan sedikit penurunan daya proteksi terhadap korosi.
Sekalipun memberikan perbaikan ketahanan oksidasi, nampak bahwa kinerja ester borat B (tabel 3) relatif lebih rendah daripada ester borat A. Kinerja ester borat $\mathrm{C}$ (tabel 4) lebih baik daripada kedua aditif sebelumnya dari segi ketahanan oksidasi, tetapi terburuk dalam perlindungan korosi, khususnya pada tembaga. Kinerja ester borat D (tabel 5) hampir sama dengan kinerja ester borat $\mathrm{C}$.

Jadi, ester borat yang mengandung nitrogen menunjukkan kinerja peningkatan ketahanan oksidasi yang lebih baik bila dibandingkan dengan ester borat tanpa nitrogen. Keberadaan nitrogen dari kandungan aditif lain (benzotriazol dan DMTD sama - sama mengandung nitrogen) nampaknya tidak memberi perbaikan. Hal ini mungkin diakibatkan oleh peningkatan stabilisasi oleh ikatan koordinasi antara atom boron dan nitrogen dari MEA dan DEA. Koordinasi antara boron dan nitrogen dari benzotriazol atau DMTD tidak terjadi karena 
rintangan sterik dan konsentrasi aditif yang relatif kecil. Mengingat kinerjanya yang hampir sama dalam uji oksidasi - korosi, penentuan aditif mana yang lebih baik harus ditentukan berdasarkan kriteria lain. Salah satu sifat penting yang mudah diamati adalah kelarutannya dalam bahan dasar.

Nampak pula secara umum bahwa terjadi penurunan proteksi terhadap logam, terutama tembaga. Hal ini terjadi karena mekanisme kerja aditif borat sama dengan mekanisme kerja bahan antikorosi. Benzotriazol berkompetisi dengan aditif borat dalam menempati permukaan logam.

Keberadaan aditif borat mengurangi kemampuan benzotriazol dalam menempati permukaan logam. Akibatnya, daya proteksi terhadap korosinya menjadi terganggu.

Tampak dari tabel 1 - 5 bahwa daya proteksi bahan dasar lebih baik daripada semua formula yang semuanya menggunakan benzotriazol sebagai bahan antikorosi. Hal ini mengarahkan pada pertanyaan tentang perlu tidaknya benzotriazol digunakan sebagai bagian dari formulasi. Hasil-hasil percobaan secara jelas menunjukkan ketidak efektifan benzotriazol sebagai bahan antikorosi pada formulasi ini. Akan tetapi, sifat korosif umumnya merupakan karakteristik dari aditif peningkat tekanan ekstrem.

\subsection{Kinerja Antioksidan}

Tabel 6 meringkaskan kinerja antioksidan i-DPA dan i-PNA pada seluruh pengujian yang dilakukan. Perbandingan secara berpasangan menunjukkan bahwa pada semua ester borat, i-PNA selalu menunjukkan kinerja yang lebih baik sebagai antioksidan. Nampak pula bahwa kedua antioksidan menunjukkan kinerja yang lebih baik bila digunakan bersama dengan ester boron bernitrogen (ester borat $\mathrm{C}$ dan $\mathrm{D}$ ) daripada ester tanpa nitrogen (ester borat $\mathrm{A}$ dan B). Hal ini menunjukkan adanya efek sinergistik antara ester borat bernitrogen dengan antioksidan amina aromatik.

\section{KESIMPULAN}

Dalam upaya mengembangkan pelumas ramah lingkungan, dilakukan formulasi bahan pelumas bio-based berupa senyawa ester berbahan baku gliserol dan asam oleat dengan 4 varian ester borat. Bahan ini selanjutnya diformulasi dengan bahan bahan antiwear / aditif tekanan ekstrem 2,5dimercapto-1,3,4-thiadiazole (DMTD) dan bahan antikorosi benzotriazol. Hasil - hasil percobaan menunjukkan bahwa ester yang diperoleh dari asam borat dan senyawa bernitrogen menunjukkan kinerja yang lebih baik daripada hasil persenyawaan antara asam borat dengan bahan dasar pelumasnya.

Pada formulasi yang dikaji, kinerja antioksidan fenil-1-naftilamin selalu lebih baik daripada kinerja difenilamin. Sekalipun secara individual terbukti efektif, peran benzotriazol sebagai inhibitor korosi pada sistem ini masih dipertanyakan karena hasilhasil percobaan menunjukkan bahwa laju korosi pada bahan dasar pelumas lebih rendah daripada laju korosi pada semua formulasi yang diuji.

\section{Ucapan Terima Kasih}

Penelitian ini didanai Direktorat Riset dan Pengabdian Masyarakat Direktorat Jenderal Penguatan Riset dan Pengembangan Kementrian Riset, Teknologi, dan Pendidikan Tinggi seuai dengan Surat Perjanjian Penugasan Pelaksanaan Hibah Penelitian No. 105/ SP2H/PPM/DRPM/II/2016 tanggal 17 Februari 2016. 


\section{DAFTAR PUSTAKA}

Ashjian H. \& Gawel H.A., "Production of borated ashless dispersants", US Pat. 4985156, Januari 1991.

Farng L.O., Horodysky A.G., \& Olszewski W.F., "Mixed alcohol/ dimercaptothiadiazole-derived hydro-xy borates as antioxidant/ anti-wear multifunctional additives", US Pat. 5137649, Agt. 1992.

Farng L.O. \& Horodysky A.G., "Aminecontaining hindered phenolic antioxidant lubricant additives and compositions thereof", US Pat. 5169547, Desember $1992 b$.

Hu J.Q., Hu Y.Q., Liu G.L., \& Ma Y.H., "Synergystic tribological per-formance of borate additive in Lubricants", Journal of ASTM International, Vol. 4 No. 8 hal. 48-56, September 2007.

Karol T.J. \& Donelly S.G., "Synergistic organoborate compositions and lubricating compositions con-taining same", US Pat No. 7897549 B2, Maret 2011.

Kirk-Othmer, "Boron-nitrogen compounds, Organic" dalam Encyclopedia of Chemical Technology, John Wiley \& Sons, 2003.

Liping X., Zhongyi H., Liang Q., Lin M., Aixi C., Sheng H., Jianwei Q. \& Xisheng F., "Synthesis, tribological and hydrolysis stability of novel benzotriazole borate derivative", Plos One, Vol 9 Issue 1, hal. 1-9, Januari 2014.

Muir R.J., "Lubricant additive containing alkyl hydroxy carboxylic acid boron esters", US Pat. 7691793 B2, 2010.

Sawyer A. W. \& Csejka D.A., "Borates esters prepared by successive reactions of boric acid with glycol", US Pat. 3914275, Oktober 1975.

Shah F.U., "Designed boron chemistry for tribological systems", Doctoral Thesis, Lulea University of Technology, 2011.
Soni S. \& Agarwal M., "Lubricants from renewable energy sources - a review", Green Chemistry Letters and Review Vol. 7, No. 4, hal. 359-384, 2014.

Wang Y.G., Li J.S. \& Ren T.H., "Tribological study of a novel borate ester containing S,P with high hydrolytic stability as a multi-functional lubricating additive", Tribology Transaction, 51:2 hal. 160-165, 2008.

Wang Y.G., Li J.S. \& Ren T.H., "Using $a$ novel disulfide compound containing boron as a potential substitute for sulfurized olefins in lubricants", Proc. IMechE Vol. 221 Part J: J. Engineering Tribology hal. 553-559, Maret 2007.

Yan J., Zeng X., van der Heide E. \& Ren T.H., "The tribological performance and tribochemical analysis of novel borat esters as lubricant additives in rapeseed oil", Tribology International Vol. 71, hal. 149-157, 2014. 